\title{
Constituição de pessoas jurídicas no Brasil e sua utilização nos modelos de negócios
}

\author{
das startups \\ Incorporation of legal entities in Brazil and their use in the business models of startups \\ Incorporación de personas jurídicas en Brasil y su uso en los modelos de negocio de startups
}

Recebido: 10/03/2021 | Revisado: 17/03/2021 | Aceito: 15/05/2021 | Publicado: 02/06/2021

Torben Fernandes Maia

ORCID: https://orcid.org/0000-0003-3053-3062

Universidade de São Paulo, Brasil

E-mail: torben@paulomaia.adv.br

Paulo Antônio Maia e Silva Junior

ORCID: https://orcid.org/0000-0003-0846-0952 Universidade Federal da Paraíba, Brasil

E-mail: paulojr@paulomaia.adv.br

José Cândido da Silva Nóbrega

ORCID: https://orcid.org/0000-0002-0976-3763

Universidade Federal de Campina Grande, Brasil

E-mail: jcandidosn@uol.com.br

Francisco das Chagas Bezerra Neto

ORCID: https://orcid.org/0000-0001-6232-4383

Universidade Federal de Campina Grande, Brasil E-mail: chagasneto237@gmail.com

\begin{abstract}
Resumo
O presente estudo vislumbra apresentar alguns apontamentos acerca dos modelos de negócios possíveis na legislação brasileira e as startups. Nessa perspectiva, este artigo, através da pesquisa exploratória, de natureza qualitativa, método dedutivo, coleta de dados documental e bibliográfica, procedeu-se de modo a realizar uma análise minuciosa do arcabouço normativo que trata acerca das startups. Além disso, foi pontuado a extrema relevância das startups, tendo em vista que são empresas com grande potencial de crescimento e, portanto, com grande potencial de contribuição para o Brasil, pois vão gerar renda, empregos, arrecadação para o Estado, movimentação da economia, entre outros. Além disso, foi abordado sobre a horizontalidade das normas fundamentais do ordenamento jurídico brasileiro, principalmente porque os contratos, para as empresas e até mesmo para os investimentos, possuem uma atribuição e compromisso com a coletividade, assim, necessita atender a função social. Por fim, salienta-se que o ordenamento jurídico brasileiro propociona ao empreendedor diversas opções de composição societária e organização da empresa, assim, a escolha do tipo de sociedade é de extrema importância para a proteção societária, gestão da empresa, atração de investimentos e manutenção da estrutura de governança.
\end{abstract}

Palavras-chave: Modelos de negócios; Startups; Movimentação da economia.

\begin{abstract}
The present study envisions a few notes about the possible business models in Brazilian legislation and startups. In this perspective, this article, through exploratory research, of a qualitative nature, deductive method, collection of documentary and bibliographic data, proceeded in order to carry out a thorough analysis of the normative framework that deals with startups. In addition, the extreme extraction of startups was scored, considering that they are companies with great growth potential and, therefore, with great potential for contribution to Brazil, as they will generate income, jobs, revenue for the State, movement of the economy, among others. In addition, it was approached about the horizontality of the fundamental norms of the Brazilian legal system, mainly because the contracts, for the companies and even for the investments, have a commitment and commitment to the community, thus, it requires to attend the social function. Finally, it should be noted that the Brazilian legal system provides the entrepreneur with several options for corporate composition and organization of the company, thus, the choice of the type of company is extremely important for corporate protection, company management, attraction of investments and maintenance governance structure.
\end{abstract}

Keywords: Business models; Startups; Economic movement.

\section{Resumen}

El presente estudio tiene como objetivo presentar algunas notas sobre los posibles modelos de negocio en la legislación brasileña y las startups. En esta perspectiva, se procedió a este artículo, a través de una investigación exploratoria, de 
carácter cualitativo, método deductivo, recolección de datos documentales y bibliográficos, con el fin de realizar un análisis detallado del marco normativo que trata sobre las startups. Além disso, foi pontuado a extrema relevância das startups, tendo em vista que são empresas com grande potencial de crescimento e, portanto, com grande potencial de contribuição para o Brasil, pois vão gerar renda, empregos, arrecadação para o Estado, movimentação da economia, entre otros. Además, se abordó sobre la horizontalidad de las reglas fundamentales del ordenamiento jurídico brasileño, principalmente porque los contratos, para las empresas e incluso para las inversiones, tienen atribución y compromiso con la comunidad, por lo que necesita cumplir con la función social. Finalmente, se enfatiza que el sistema legal brasileño brinda al empresario varias opciones para la composición corporativa y organización de la empresa, por lo que la elección del tipo de empresa es de suma importancia para la protección corporativa, la gestión de la empresa, la atracción de inversiones y la gobernanza del mantenimiento. estructura.

Palabras clave: Modelos de negocio; Inauguración; Movimiento económico.

\section{Introdução}

O atual contexto global econômico, social e jurídico é fortemente impulsionado pelos avanços da tecnologia, que atingiram nos dias atuais o auge da sua performance, acelerando e reformulando completamente os mais variados institutos e instituições sociais. Boa parte de tudo isso é proporcionado pelas startups, que são companhias parte do gênero das empresas, apresentado, todavia, particularidades que a tornam diferentes das demais.

Inseridas dentro de um ecossistema próprio, em que há forte presença da colaboração, economistas e agentes do mercado já falam em uma economia colaborativa, que começa a ganhar espaço, por ser um modelo mais altruísta, que está democratizando o acesso a bens e serviços, reduzindo radicalmente os custos do acesso e da produção, possibilitando o ingresso de novos players.

Pessoas que até então tinham boas ideias, mas que desprovidos de capital, não conseguiam tocar um projeto empreendedor, conseguem tirar o projeto do papel com mais facilidade e torná-lo realidade. Infelizmente, isso não é fruto de uma conversão de um modelo econômico capitalista selvagem para um sistema humanitário, caridoso e filantrópico. Mas sim, porque o capital do mercado financeiro está voltado para as startups que se consolidaram, e que se tornaram nos últimos anos as líderes do ranking das corporações mais valiosas do mundo.

Assim, se tornou extremamente interessante apostar dinheiro nelas, pois o eventual sucesso dessas é capaz de produzir rendimentos inalcançáveis em outros investimentos. A quarta revolução industrial, pela qual a humanidade atravessa, já é a maior de todas. Inteligência artificial, internet das coisas, realidade aumentada, nanotecnologia, big data, etc., são produtos e ao mesmo tempo combustíveis das startups, empresas cuja diferença está na disrupção, inovação, escalabilidade e principalmente no modelo de negócios pioneiro.

Todavia, há uma presença, de maneira ainda mais acentuada, dos riscos e incertezas, sobretudo pela inovação e ausência de precedentes de sucesso, de modelos de negócios que possam guiar os caminhos da companhia que aposta na novidade. Não é pelo fato de lidar com tecnologia ou em virtude do tamanho que uma empresa será definida como startup, mas especialmente por lidarem com uma realidade de produção, de clientela, de estratégia de marketing tão inovadora, que os modelos de negócios tradicionais não podem ser aproveitados por ela.

A sua importância para a economia está no fato da capacidade que elas possuem de afetar profundamente mercado pelo qual se inserem em virtude da disrupção proporcionada por elas. A escalabilidade e repetibilidade são fenômenos que as tornam gigantes em questão de tempo.

Tendo em vista a relevância do tema proposto, será realizada uma pesquisa exploratória, que tem por objetivo proporcionar uma maior familiaridade com o problema. Sem a perspectiva de esgotamento do tema, tratar-se-á, sobretudo, acerca dos modelos de negócios possíveis na legislação brasileira. Ademais, se utilizará do método de abordagem dedutivo, uma vez que se buscará os resultados a partir da análise geral até concluir de maneira particular a hipótese. Quanto à natureza da pesquisa, esta será qualitativa, buscar-se-á analisar e interpretar os institutos do Direito Empresarial, como forma de chegar à conclusão que as startups são de extrema relevância para o crescimento econômico. 
Quanto ao método de procedimento, atribuir-se-á o método monográfico, partindo de um estudo profundo sobre as startups, que podendo esta pesquisa ser considerada representativa de muitos outros ou mesmo de todos os casos semelhantes. Além do mais, quanto aos procedimentos técnicos, se delineará o presente estudo por meio de pesquisa bibliográfica e documental, tendo em vista que se buscará, através da renomada doutrina do direito e periódicos especializados, bem como através da interpretação das leis, a solução para desburocratizar o processo de constituição da pessoa jurídica e impulsionar o crescimento econômico.

No presente manuscrito, portanto, serão apresentados alguns apontamentos acerca dos modelos de negócios possíveis na legislação brasileira e as startups. Não obstante, será abordado o arcabouço normativo destas. Nesse contexto, vale salientar a extrema importância das startups para a geração de emprego e renda.

\section{Desenvolvimento}

É inegável o papel que desempenham as empresas e os empresários em uma sociedade, bem como a legitimidade que se possui na busca pelo lucro e rendimento de seus investimentos. É, sobretudo, pela responsabilidade, muitas vezes excessiva, que carrega o empreendedor que opta por exercer essa importante vocação para uma nação, que é a encarregada precipuamente de coordenar a cadeia que produz as riquezas e faz a economia girar, gerando empregos e tributos, esse último responsável por financiar a máquina estatal.

No Brasil, infelizmente não se pode negar o que popularmente se convencionou chamar de "Custo Brasil", em referência às burocracias enfrentadas e à alta carga tributária paga pelo setor produtivo empresarial. Todavia, esse discurso não pode ser utilizado para autorizar a prática de injustiças sociais, concentração de renda prejudicial à população e violação na dignidade da pessoa humana, sobretudo porque existe para os contratos, para as empresas e até mesmo para os investimentos, que é o objeto principal de discussão deste trabalho, uma função e compromisso com a coletividade que emana da carga axiológica positivada no texto legal de maior envergadura do sistema jurídico brasileiro.

Nas palavras de Celso Antônio Bandeira de Mello (2007, p. 943):

violar um princípio é muito mais grave do que transgredir uma norma qualquer. A desatenção ao princípio implica ofensa não apenas a um específico mandamento obrigatório, mas a todo o sistema de comandos. É a mais grave forma de ilegalidade ou inconstitucionalidade, conforme o escalão do princípio atingido, porque representa insurgência contra todo o sistema, subversão dos seus valores fundamentais, contumélia irremissível ao seu arcabouço lógico e corrosão de sua estrutura mestra.

Assim, é inegável a imperatividade e normatividade à base principiológica do ordenamento jurídico. Segundo Luís Roberto Barroso, a constitucionalização do Direito Civil foi resultado da fixação constitucional da dignidade da pessoa humana como plataforma a ser perseguida, o que fez com que direitos fundamentais de previsão constitucional passassem a ter aplicabilidade sobre as relações privadas (Barroso, 2006).

Em decorrência da complexidade das relações obrigacionais, que lideradas a partir do Código Civil de 2002 pela boafé objetiva, fez com que os contratos passassem a ser compostos também pelos deveres anexos e laterais inseridos invariavelmente, em decorrência do interesse social de que os pactos sejam baseados pela cordialidade, lealdade, confiança e na promoção de um relacionamento saudável no decorrer e execução dos contratos.

Com o crescimento das startups e o respectivo aumento da demanda, é preciso mais pessoas trabalhando para absorver a procura dos eventuais consumidores, o que implica em contratar mais trabalhadores. Consequentemente, mais pessoas estarão recebendo renda e salário, aumentando o seu poder de compra, garantindo a sua subsistência, provendo suas necessidades, consumindo e gerando tributos. 
O aumento das operações da empresa provoca crescimento no faturamento, fazendo com que o montante sobre o qual incidirão os respectivos tributos municipais, estaduais e federais seja também maior, proporcionando uma maior arrecadação fiscal para o estado, o qual disporá de maior lastro financeiro para promover saúde, educação, segurança, distribuição de renda e justiça social para toda a coletividade.

Essa roda quando começa a se multiplicar em várias empresas e startups que dão certo, é capaz promover grandes impactos sociais, e é por isso que se fala da função social, por conta da sua capacidade peculiar de promover o sucesso de empresas e do potencial proveito que a sociedade terá caso isso aconteça.

Entretanto, é difícil a missão de equalizar os interesses materiais das partes que estão diretamente envolvidas na criação das startups. Isso porque, em algum momento, os interesses podem entrar em rota de colisão. Obviamente que ambos almejam o sucesso comum, pois de maneira imediata será também a glória individual.

Todavia, existem casos em que parte das intenções dessas partes envolvidas se chocam. Ou até mesmo podem não se colidir, mas existe uma vantagem demasiada para uma das partes e uma onerosidade excessiva para outra, o que parece não ser esse o interesse da sociedade.

É por essa razão que se tomam emprestadas as palavras de Rodrigo Toscano de Brito quando escreveu sobre a equivalência material dos contratos ou equilíbrio econômico do contrato, princípio social que decorre da função social e boa-fé objetiva, com previsões no Código Civil brasileiro.

O princípio da eticidade, sem embargo, autoriza que o legislador busque, na relação jurídica concreta, a aplicação do princípio da concretude, ou seja, pode o magistrado, em dada discussão contratual, perquirir sobre o que é justo e procurar o equilíbrio da contratação que esteja, eventualmente, arrebatada por um desequilíbrio, beneficiando uma das partes, e prejudicando a outra. (Brito, 2007, p. 59).

Há que se prestar as devidas homenagens aos princípios da segurança jurídica e do pacta sun servanda, que são pilares que tornam as relações sociais serenas e estáveis, instrumentos também de equidade do direito, mas que não podem servir a dois senhores. Isso porque a boa-fé objetiva, que compõe o conjunto recheado da base ética dos contratos, não permite o adimplemento ruim sob qualquer condição, com a alegação de liberdade e igualdade entre os contratantes e o seu cumprimento inconsequente.

Merecem destaque as palavras do ministro do Supremo Tribunal Federal, Luiz Edson Fachin, quando foi questionado acerca do instituto da segurança jurídica:

A segurança jurídica é muito importante, mas não se esgota no âmbito da estabilidade formal do pactuado. Ela também diz respeito ao aspecto material da garantia do equilíbrio entre direitos, deveres, ônus e benefícios distribuídos às partes ao longo de todo o processo contratual. Pensar em segurança jurídica como estabilidade meramente formal é uma visão reducionista do fenômeno, pois o contrato se insere em um processo obrigacional dinâmico no qual a estabilidade da relação de equilíbrio engendrada no momento da celebração deve, sem embargo, ser mantida, ainda que com modificação do formalmente pactuado. Trata-se de uma dimensão material da segurança. De outro lado, a segurança jurídica deve abarcar também a higidez do ordenamento jurídico centrado nos direitos fundamentais constitucionalmente garantidos. Não há segurança jurídica formal do contrato contra a segurança jurídica na proteção dos direitos fundamentais. Isso significa que um contrato que, desde a gênese, contraria princípios dessa natureza, não atende aos preceitos normativos mais básicos do ordenamento. Para esse contrato, não há, mesmo, segurança jurídica formal, porque ofende o cerne de todo o sistema jurídico. De outro lado, a segurança formal complementa e chancela o contrato equilibrado, celebrado "de" e "conforme" a boa-fé, e que não ofende aos direitos fundamentais. Demais disso, a segurança jurídica é mesmo princípio relevante, mas que pode ceder ante outros valores normativamente assegurados pelo ordenamento. (Fachin, 2009, s/n).

Sabendo da importância desse instituto jurídico, que é responsável em grande parte pela estabilidade, garantia e solidez das relações jurídicas, que legitimam a execução das obrigações, ainda que a contragosto de um dos contratantes, e também da sua relevância para o mercado financeiro e de investimentos, esse não pode ser um apelo e discurso legitimador que violem valores supremos e fundamentais da sociedade. 
Assim, "o legislador permite que o juiz, mediante cláusulas abertas que existem à sua disposição, atue concretamente para obter a melhor solução para o caso, levando em consideração a função social do instituto em discussão” (Brito, 2007, p. 8). Segundo Marcos Ehrshardt Jr. (2019, p. 99), quando escreveu sobre os impactos da boa-fé objetiva no direito societário, esclareceu que desse instituto decorrem os seguintes deveres:

a) Dever de proteção, que impõe às partes a obrigação de prevenir danos, tanto em relação ao objeto da prestação como também em relação às esferas jurídicas das partes e eventualmente de terceiros, e se desdobra na exigência da manutenção de um comportamento diligente; exigência de velar pelo adequado fluxo da relação jurídica obrigacional com cuidado, previdência e segurança.

b) Dever de informação, que impõe às partes a obrigação de advertir, explicar, esclarecer, avisar, prestar contas, sempre que se fizer necessário, em especial quando da ocorrência de circunstâncias ainda desconhecida da outra parte, mas necessária ao pleno desenvolvimento da relação jurídica obrigacional na direção do melhor adimplemento possível. c) Dever de cooperação, que impõe às partes a obrigação de mútuo auxílio na superação de eventuais obstáculos surgidos em qualquer fase do desenvolvimento da relação jurídica obrigacional, por vezes confundindo-se com a exigência de fidelidade e lealdade entre as partes contratantes, que entre outras condutas pode ensejar o dever de omissão e segredos de informações obtidas no iter obrigacional para preservar de interesses comuns ou específicos de um dos figurantes.

Com relação ao dever de confiança, lealdade e transparência, há um interessante julgado do STJ sobre o tema, onde restou consignada a relevância desses valores para a economia nacional e internacional, em função do seu papel desempenhado para a construção da segurança e transparência das operações financeiras.

Trata-se do Recurso Especial n 1130103 de origem do estado do Rio de Janeiro, que teve como recorrente família então proprietária de holding que era sócia administradora e gestora da então pessoa jurídica "PERDIGAO AGROINDUSTRIAL S/A". Através de denúncia da revista VEJA, os familiares se tornaram alvos de um inquérito administrativo que tramitou perante a Comissão de Valores Imobiliários - CVM do Brasil, sob a acusação de terem feito registrar crédito de mútuo obtido junto à holding, familiares em favor daquela empresa como se fosse saldo a receber de clientes, ao invés de considerá-lo como mútuo, maquiando toda uma operação financeira.

Assim, cada um dos autores da ação judicial foi condenado pela autarquia a pagar uma multa no valor de R\$ 4.428.977,00 (quatro milhões, quatrocentos e vinte e oito mil, novecentos e setenta e sete reais) além de ficarem inabilitados para exercício do cargo de administrador de companhia aberta por dez anos.

Insatisfeitos com a condenação administrativa, buscaram no judiciário a reforma da decisão da CVM visando à anulação da multa, alegando ilegitimidade e ilegalidade da penalidade, sob o pretexto de inexistência de conduta ilícita, e que o montante fixado seria supostamente desproporcional em relação ao desvalor da conduta e aos elementos fáticos do caso concreto.

O pedido em primeiro grau foi julgado improcedente, cuja sentença foi mantida pelo Tribunal Recursal ordinário. Ato contínuo, foi interposto recurso especial julgado pelo STJ, cuja fundamentação pelo não provimento do recurso merece destaque.

Inicialmente, o voto do relator que foi seguido pelo colegiado restou consignado que a apreciação por parte do Poder Judiciário da atuação administrativa deve ser razoável, de modo a não substituir o mens legis, e inovar além do previsto pelo Poder Legislativo, sob pena de usurpar as funções deste e denegrir o regime de tripartição de poderes.

Além do mais, ficou registrado também nessa manifestação de que houve falta de transparência na gestão das operações da empresa, cujo procedimento investigado provocou impacto sobre o patrimônio da companhia, que por ser de capital aberto, tem o dever de informação aos seus acionistas.

Não deve ser outro raciocínio a ser utilizado, vez que as empresas, conforme já fortemente discutido previamente neste trabalho, desempenham uma função social. No caso de pessoas jurídicas que fazem opção por capital aberto negociado na bolsa de valores, a incidência da probidade e transparência deve ser ainda maior, posto que há uma cúpula que dita os rumos desta, 
mas sob a batuta dos demais investidores e proprietários, reconhecidos como acionistas, que depositam sua confiança e esperam reciprocidade nessa relação.

Há um interesse da coletividade e da sociedade de que as coisas caminhem bem na saúde financeira do setor empresarial, haja vista o papel que essas desempenham no cenário econômico nacional e internacional, de modo que a ética nas relações internas da corporação é um bem jurídico que deve ser tutelado pelo estado, pois está, em ultima ratio, estimulando a segurança e transparência nas operações empresariais. E isso ficou apontado no voto vencedor, o qual se destaca:

A Lei das Sociedades por Ações também é informada por essa principiologia, como se extrai da Exposição de Motivos n. ${ }^{\circ} 196$, de 24 de junho de 1976, segundo a qual a responsabilidade social que passou a ser exigida dos acionistascontroladores e dos administradores das pessoas jurídicas impõe-lhes comportamento idôneo e probo. (STJ - REsp: 1130103 RJ 2009/0054605-4, Relator: Ministro CASTRO MEIRA, Data de Julgamento: 19/08/2010, T2 - SEGUNDA TURMA, Data de Publicação: DJe 30/08/2010).

Conceitos como governança corporativa já dominam os espaços do setor empresarial, cada vez mais marcados pela consciência de deveres com o meio ambiente, direitos humanos, sustentabilidade, ética empresarial, cidadania corporativa e responsabilidade social corporativa. Isso provoca para as tomadas de decisões empresariais a atenção com demandas que transcendem a esfera da performance financeira, gerando expectativa tanto para o âmbito interno da empresa, quanto para os consumidores, fornecedores, agências governamentais de fiscalização (Ehrhardt Jr., 2019).

Assim, o fenômeno da boa-fé começa a produzir efeitos sobre a governança corporativa e a gestão de riscos, interseção que toca o setor de investimentos em startups. É que esse instituto civil em algum momento impacta nas decisões do negócio. Adriana Andrade e José Paschoal Rossetti oportunamente dissertaram sobre os princípios da governança corporativa, os quais possuem nítida relação com os deveres decorrentes da boa-fé objetiva. São eles: transparência (disclousure), isonomia (fairness), prestação de contas (accountability) e responsabilidade corporativa (compliance) (Andrade \& Rossetti, 2014).

Dever de informação, prestação de contas e transparência são verdadeiras imposições de importância elevada para uma convivência saudável dentro de uma relação comercial. Disponibilização de dados e linguagem acessível, com o tempo e o espaço necessário para a interpretação do momento são fundamentais para a tomada de decisões, esclarecimentos e advertências.

A criação e constituição dessas corporações é juridicamente muito parecida com a das demais empresas, com a estrutura base idêntica, com exceção de cláusulas e termos específicos que podem vir a ser acrescidos para atender às demandas peculiares do ecossistema, sobretudo as exigências de investidores.

Nesse sentido, este tópico do trabalho irá focar suas atenções em discutir os riscos e os limites que cercam o investidoranjo em startup que irá variar de acordo com a opção jurídica escolhida para operar o seu investimento, e o impacto que essa escolha irá provocar sobre as mais variadas relações jurídicas que a empresa vai desenvolver, e como isso pode alcançar ou não o financiador.

A análise dos tipos de sociedade ofertados pela legislação brasileira tem a sua importância para o presente trabalho, uma vez que a startup, embora seja uma espécie peculiar de empresa, deve ser configurada dentro do cardápio de opções existentes no Código Civil brasileiro.

Dentre todos esses pontos, a devida atenção deve ser dada nessa configuração, que pode ter impacto até mesmo na atração de investimentos, com enfoque principal dos investidores-anjos, cujos reflexos irão atingir as responsabilidades societárias sobre esses financiadores. É de grande importância que os empreendedores façam a proteção jurídica de seus negócios. Infelizmente, a ansiedade dos empreendedores em começar a operar a sua ideia muitas vezes compromete a regularização e formalização da empresa. Nessa esteira destacam-se as palavras de Nybo (2016, s/n) que muito agregam sobre este aspecto: 
A ansiedade dos empreendedores em operacionalizar sua ideia não pode superar a necessidade de organização do relacionamento a ser estabelecido entre eles no momento em que estes se aventuram a criar um projeto em cooperação. No momento em que os empreendedores se reúnem com o objetivo de construir uma startup, é necessário que estes se organizem e, para isto, torna-se necessária a utilização de instrumentos jurídicos capazes de regular a relação que se estabelecerá entre eles.

Embora o arcabouço legal brasileiro permita a alteração da estrutura societária após o seu registro, a reformulação ocorre de maneira muito burocrática e penosa, o que reforça a importância de escolha.

No Brasil, as empresas podem ser de estrutura individual, nos formatos de microempreendedor individual, empreendedor individual ou EIRELI. A outra estrutura é na modalidade de sociedades, que podem ser formatadas em: "sociedade comum, em conta de participação, simples, em nome coletivo, em comandita simples, em comandita por ações, Limitada e Anônima" (Rebelo, 2013).

Para as startups, embora seja possível, não é aconselhável a opção em formato de empresa individual, haja vista que futuramente ela poderá vir a ser financiada e incorporar um novo sócio, fazendo com que ela seja conduzida a reformular sua estrutura formal, uma vez que essa operação não é permitida para empresas individuais. Isso porque a logística na prática de startups faz com que essas companhias se constituam geralmente por mais de um sócio:

Um empreendimento de startup é normalmente de propriedade de um ou mais indivíduos ou entidades, cada um fazendo uma contribuição ou um investimento no negócio em retorno para participação acionária (porcentagem de propriedade). Os indivíduos ou entidades que formam o empreendimento geralmente são chamados de fundadores. Em geral, os indivíduos ou entidades que possuem o empreendimento são referidos como "principais", "proprietários" ou "participantes de capital". Indivíduos ou entidades que fazem contribuições para o negócio depois que ele foi formado são chamados de "investidores" ou "credores"1(Duening, Hisrich, \& Lechter, 2015, s/n, tradução nossa).

A carência de recursos financeiros no início das operações de uma startup faz com que o(s) fundador(es) optem pela remuneração de parceiros essenciais através de participação societária, como acontece através de contratos de vesting ou até o mesmo o bootstrapping, explorando ao máximo as habilidades disponíveis em cada membro da equipe.

Desse modo, a utilização de empresário individual, microempreendedor individual e EIRELI são as estruturas formais menos utilizadas. Além do mais, a figura de investidores externos é sempre presente nesse meio. Diante dos casos em que as habilidades dos membros internos não sejam suficientes, a captação de recursos de terceiros pode ser formalizada através do mútuo conversível, cessão de quotas ou ações societárias ou outras modalidades vistas anteriormente, em que o investidor passa a integrar o capital da empresa na qualidade de sócio.

Até mesmo em casos em que a sociedade é formada por membros minoritários, há a figura do vesting, onde se estipulam cláusulas contratuais que projetam um crescimento progressivo do percentual da participação societária, mediante termos preestabelecidos.

Uma outra possibilidade, trata-se da sociedade limitada. É um modelo regulado pelos arts. 1.052 a 1.087 do Código Civil, e suplementada pela Lei n ${ }^{\circ}$ 6.404, de 1976, conhecida como a Lei das Sociedades Anônimas. Trata-se de uma união de pessoas, onde diferentemente do que acontece nas sociedades anônimas que têm como ânimo predominante diretamente o capital, a LTDA tem como princípio norteador o affectio societatis.

\footnotetext{
${ }^{1}$ Texto original se encontra em inglês, cuja versão segue: "A start-up venture is typically owned by one or more individuals or entities, each making a contribuition to or an investiment in the business in returno for equity interest (percentage of ownership). The individuals or entities tha initilly form the venture are generally referred to as the founders. In general, the individuals or entities tha own the venture are referred to as the "principals", "owners", ou "equity participants". Individuals or entities that make contributions to the business after it has been formed are referred to as "investors" or "lenders".
} 
Ela pode ainda se organizar como uma sociedade limitada simples, para as empresas que irão se dedicar aos trabalhos intelectuais, fazendo o registro do respectivo ato constitutivo no registro civil de pessoas jurídica, ou como uma sociedade limitada empresarial, que exerce atividade empresarial, com registro nas juntas comerciais.

Como regra, a responsabilidade dos sócios será limitada aos valores das respectivas quotas integralizadas. Porém, todos os sócios respondem solidariamente pela totalidade das quotas da sociedade.

Ademais, revela-se a opção indicada para empreendedores que possuem um capital social mínimo, estando aptos a instaurar o formato de Empresa Individual de Responsabilidade Limitada (EIRELI), distinguindo-se da MEI, em especial, no que se refere à responsabilidade patrimonial, conquanto se revele limitada ao capital social inicialmente ancorado, protegendo o patrimônio pessoal do instituidor de eventuais fracassos do negócio por ele idealizado.

A burocracia menor se justifica na medida em que se exige do empresário apenas que: a) a atividade social esteja em consonância com lista disponibilizada pela Receita Federal; b) que seja preenchido o cadastro e; c) que seja quitado o carnê inicial.

Há de se reconhecer, portanto, que embora não sejam as modalidades mais comuns, existe sentido na constituição de startups por modelos empresariais consubstanciados em uma só pessoa. Em outro polo, quando se constata uma pluralidade de sujeitos adentra-se nos formatos societários propriamente ditos, dentre os quais se ressaltam: a sociedade anônima e a sociedade limitada. Nas palavras de Maria Helena Diniz (2013, p. 358):

a sociedade limitada é, no Brasil, a forma societária mais comum das sociedades simples e empresárias por haver limitação de responsabilidade do sócio-quotista ao montante do capital social por ele subscrito ou pelo total do capital social até que se dê sua integralização.

Configura-se como um modelo regulado pelos arts. 1.052 a 1.087 do Código Civil, e suplementada pela lei 6.404 de 1976 (Lei das Sociedade Anônimas) e tem como um de seus grandes elementos o cunho personalista (affectio societatis), revelado na estrutura de seu contrato social, bem como através dos acordos de quotistas para sua organização de controle e administração (Diniz, 2013).

Segundo a Associação Brasileira de Startups (ABS), é o formato mais utilizado por empreendedores que estão começando com outros sócios, conquanto possua um custo reduzido e compatível com o regime de tributação do Simples Nacional. Ademais, pontua-se que para constituir uma Sociedade Limitada é preciso preparar o seu Contrato Social (documento que define o acordo e as responsabilidades dos sócios).

A sociedade anônima, por sua vez, constituída por estatuto social, é o tipo societário que predomina o intuitu pecuniae, (em detrimento do intuitu personae), na medida em que há limitação da responsabilidade dos acionistas ao preço de emissão das ações por eles subscritas ou adquiridas e livre transferência das ações sociais (Diniz, 2013, p. 465).

A ABS aponta este formato empresarial como sendo a melhor opção para startups que anseiem por investimentos, na medida em que permite uma classe de acionistas, ainda que seja modelo mais rígido e custoso que os anteriormente analisados.

Há que se reconhecer que diante dos casos em que as habilidades dos membros internos não sejam suficientes, a captação de recursos de terceiros pode ser formalizada através do mútuo conversível, cessão de quotas ou ações societárias ou outras modalidades vistas anteriormente, em que o investidor passa a integrar o capital da empresa na qualidade de sócio.

Até mesmo casos em que a sociedade é formada por membros minoritários, há a figura do vesting, em que se estipulam cláusulas contratuais que projetam um crescimento progressivo do percentual da participação societária, mediante termos preestabelecidos. 


\section{Considerações finais}

Percebe-se, mediante considerações abordadas durante o texto, que o empreendedorismo inovador, aliado com a tecnologia, possui grande capacidade para desenvolver um país. Nesse contexto, pontua-se que a relação entre o Direito e o Estado podem fornecer para o ecossistema empreendedor no Brasil é muito grande, sobretudo porque a influência sobre o mercado é gigantesca, e quando bem direcionada, traz consequências positivas para toda a nação.

Ademais, destaca-se que o ordenamento jurídico brasileiro, através da codificação civilista e legislações complementares, oferece ao empreendedor diversas opções de composição societária e organização da empresa, em que se atribui a cada uma delas normas específicas e diferentes graus de governança e responsabilidade. Assim, a escolha do tipo de sociedade é de extrema importância para a proteção societária, gestão da empresa, atração de investimentos e manutenção da estrutura de governança.

Nesse diapasão, levando em consideração essa necessidade de assegurar, de forma eficaz, o crescimento econômico inerente ao mercado, acreditamos que investigações como esta devem ser prosseguidas. Sendo assim, como sugestão para continuidade de discussões nesse sentido, analisar, à luz do Direito Empresarial, de que modo as formas de constituição de pessoas jurídicas no Brasil podem ser implementadas com o fito de melhorar o desempenho das startups.

\section{Referências}

Andrade, A., \& Rossetti, J. P. (2014). Governança corporativa. (4a. ed.): Atlas.

Barroso, L. R. (2006). O novo direito constitucional e a constitucionalização do direito. In: Coutinho, J. Nelson de M., Lima, M. Mont'A. B. (coord.). Diálogos constitucionais: direito, neoliberalismo e desenvolvimento em países periféricos. Rio de Janeiro: Renovar.

Brito, R. T. (2007). Equivalência material dos contratos - civis, empresariais e de consumo: Saraiva.

Diniz, M. H. (2013). Curso de direito civil brasileiro. v. 8: direito de empresa. (5a. ed.): Saraiva.

Duening, T., Hisrich, R., \& Letchter, M. (2015). Tecnology Entrepreunership: Taking Innovation to the Marketplace. Oxford: Elsevier, 2015.

Ehrhardt, J. R. M. (2019). Quais os impactos da boa-fé objetiva no direito societário? In: Tepedino, G., Teixeira, A. C. B., Almeida, V. (coord.). Da dogmática à efetividade do Direito Civil. Anais do Congresso Internacional de Direito Civil Constitucional; IV Congresso do IBDCivil. (2 ${ }^{\mathrm{a}}$. ed.) rev., ampl. e atual. Belo Horizonte: Fórum.

Fachin, L. E. (2009). Entrevista: Contrato e Ordem Pública. Carta Forense. <http://www.cartaforense.com.br/conteudo/entrevistas/contrato-e-ordempublica/5001>.

Mello, C. A. B. Curso de Direito Administrativo. In: BRITO, Rodrigo Toscano de. Equivalência material dos contratos - civis, empresariais e de consumo: Saraiva, 2007.

Nybo, E. F. (2016). Memorando de entendimentos para a pré-constituição de uma startup. In: JÚDICE, L. P. (org.). Direito das Startups: Juruá.

Rebelo, N. S. A. (2013). A Sociedade Empresária e a Captação de Recursos de Private Equity e Venture Capital: Estudo Interdisciplinar do Financiamento Empresarial: Buqui.

STJ - REsp: 1130103 RJ 2009/0054605-4, Relator: Ministro Castro Meira, Data de Julgamento: 19/08/2010, T2 - Segunda Turma, Data de Publicação: DJe 30/08/2010. 